\title{
Origin of Enhanced Thermal Atomic Layer Etching of Amorphous $\mathrm{HfO}_{2}$
}

\author{
Running title: Origin of Enhanced Thermal Atomic Layer Etching of Amorphous $\mathrm{HfO}_{2}$ \\ Running Authors: Mullins et al. \\ Rita Mullins ${ }^{1}$; José Julio Gutiérrez Moreno² and Michael Nolan 1,a) \\ ${ }^{1}$ Tyndall National Institute, University College Cork, Cork T12 R5CP, Ireland. \\ ${ }^{2}$ Barcelona Supercomputing Center (BSC), C/Jordi Girona 31, 08034 Barcelona, Spain \\ a) Electronic mail: michael.nolan@tyndall.ie
}

\section{Abstract}

$\mathrm{HfO}_{2}$ is a high- $k$ material that is used in semiconductor devices. Atomic-level control of material processing is required for the fabrication of thin films of high- $k$ materials at nanoscale device sizes. Thermal atomic layer etching (ALE) of metal oxides, in which up to one monolayer of material can be removed, can be achieved by sequential self-limiting (SL) fluorination and ligand-exchange reactions at elevated temperatures. First-principles based atomic-level simulations using density functional theory (DFT) can give deep insights into the precursor chemistry and the reactions that drive the etch of metal oxides. A previous study examined the hydrogen fluoride (HF) pulse in the first step in the thermal ALE process of crystalline $\mathrm{HfO}_{2}$ and $\mathrm{ZrO}_{2}$. This study examines the $\mathrm{HF}$ pulse on amorphous $\mathrm{HfO}_{2}$ using first-principles simulations. The Natarajan-Elliott analysis, a thermodynamic methodology is used to compare reaction models representing the selflimiting and spontaneous etch processes taking place during an ALE pulse. For the HF pulse on amorphous $\mathrm{HfO}_{2}$, we found that thermodynamic barriers impeding spontaneous etching are present at ALE relevant temperatures. HF adsorption calculations on the amorphous oxide surface is studied to understand the mechanistic details of the HF pulse. A HF molecule adsorbs dissociatively by forming Hf-F and $\mathrm{O}-\mathrm{H}$ bonds. HF coverages ranging from $1.1 \pm 0.3$ to $18.0 \pm 0.3 \mathrm{HF} / \mathrm{nm}^{2}$ are investigated and a mixture of molecularly and dissociatively adsorbed HF molecules is present at higher coverages. A theoretical etch rate of $-0.82 \pm 0.02 \AA$ /cycle for amorphous $\mathrm{HfO}_{2}$ was calculated using a maximum coverage 
of $9.0 \pm 0.3 \mathrm{Hf}-\mathrm{F} / \mathrm{nm}^{2}$. This theoretical etch rate is greater than the theoretical etch rate for crystalline $\mathrm{HfO}_{2}$ that we previously calculated at $-0.61 \pm 0.02 \AA /$ cycle. Undercoordinated atoms and void regions in amorphous $\mathrm{HfO}_{2}$ allows for more binding sites during fluorination whereas crystalline $\mathrm{HfO}_{2}$ has a limited number of adsorption sites.

\section{INTRODUCTION}

Atomic layer processing has become increasingly important due to the continued downscaling of semiconductor devices, which necessitates deposition of thinner materials films in complex structures. The control of film etch offered by thermal atomic layer etching (ALE) is necessary for state-of-the-art semiconductor devices. ${ }^{1}$ Thermal ALE is a technique that removes thin layers of material using sequential, self-limiting surface reactions and can be viewed as the reverse of atomic layer deposition (ALD). ${ }^{2}$ Thermal ALE is based on surface modification and volatilization reactions, where the modification step alters the surface layer into a non-volatile later followed by the release of volatile etch products from the surface layer in the second reaction. ${ }^{2}$ For metal oxides, thermal ALE has been performed using fluorination and ligand exchange reactions as shown in Figure $1 .{ }^{3}$ Fluorination converts the surface of the metal oxide to a surface fluoride layer and ligand exchange can volatilize the metal fluoride layer to produce stable etch products. Thermal ALE relies on temperature and thermochemically favourable reactions to remove surface species ${ }^{4}$ and etches at the same rate in all directions. ${ }^{5}$ Many technologically important metal oxides have been etched using thermal ALE including $\mathrm{HfO}_{2},{ }^{6-9} \mathrm{ZrO}_{2},{ }^{6,9} \mathrm{SiO}_{2},{ }^{10}$ $\mathrm{Al}_{2} \mathrm{O}_{3},{ }^{9,11-17} \mathrm{TiO}_{2},{ }^{18} \mathrm{VO}_{2},{ }^{19} \mathrm{WO}_{3},{ }^{20} \mathrm{ZnO},{ }^{21} \mathrm{Ga}_{2} \mathrm{O}_{3},{ }^{22}$ as well as metal nitrides such as 
$\mathrm{Si}_{3} \mathrm{~N}_{4},{ }^{23} \mathrm{AlN},{ }^{24} \mathrm{TiN},{ }^{25,26}$ and GaN. ${ }^{27,28}$ Thermal ALE of amorphous $\mathrm{Al}_{2} \mathrm{O}_{3}$ has also been reported using $\mathrm{NbF}_{5}$ to replace $\mathrm{HF}$ as the fluorination agent and $\mathrm{CCl}_{4}$ for the halideexchange reaction. ${ }^{29}$ As well as fluorination and ligand-exchange, thermal ALE can also be performed by other processes such as conversion, ${ }^{21}$ oxidation ${ }^{25}$ oxidation/chlorination ${ }^{30}$ and chlorine-fluorine ligand exchange. ${ }^{31}$ Advantages of ALE include high uniformity, the ability to etch high-aspect-ratio features, selectivity, and smoothing. ${ }^{32}$

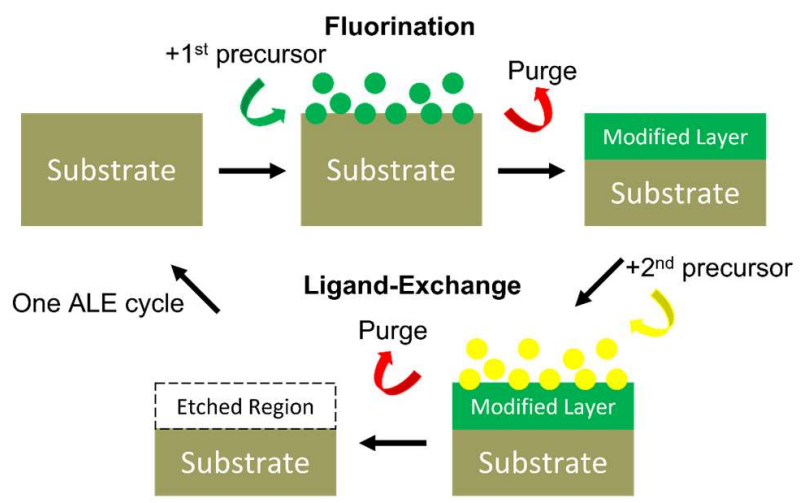

Figure 1. Schematic model of the thermal ALE process.

Semiconductor devices have features at the nanometer scale due to Moore's Law scaling. $\mathrm{SiO}_{2}$ gate dielectrics are so thin that electron tunnelling through the dielectric layer, which leads to high leakage currents, is impossible to avoid. ${ }^{33,34} \mathrm{HfO}_{2}$ is a high- $k$ material with a dielectric constant of 22 ; it allows a high drive current to be maintained, while minimized leakage current meaning that a low equivalent oxide thickness can be used. ${ }^{35}$ $\mathrm{HfO}_{2}$ is thermodynamically stable when interfaced with silicon in semiconductor devices. ${ }^{36,37}$ Amorphous $\mathrm{HfO}_{2}$ has a dielectric constant of $\sim 16$ to $19 .{ }^{38}$

In terms of mechanisms, thermal ALE processes generally use HF for the fluorination step ${ }^{25}$ for metal oxides as it is a useful nucleophilic fluorination reactant ${ }^{19}$ in 
which the fluoride anion serves as the active reaction species. For the ligand-exchange step examples of metal precursors used are $\mathrm{Sn}(\mathrm{acac})_{2},{ }^{6} \mathrm{Al}\left(\mathrm{CH}_{3}\right)_{3},{ }^{6,39} \mathrm{Al}\left(\mathrm{CH}_{3}\right)_{2} \mathrm{Cl}^{6}{ }^{6} \mathrm{SiCl}_{4},{ }^{6}$ $\mathrm{BCl}_{3},{ }^{31} \mathrm{TiCl}_{4}{ }^{8}$ and $\mathrm{WF}_{6}{ }^{40}$. The surface fluorination step in thermal ALE using HF is the focus of our work and the focus of this paper.

Experimental studies have shown that crystalline films have lower etch rates than amorphous films for thermal ALE of metal oxides $\mathrm{HfO}_{2}, \mathrm{ZrO}_{2}, \mathrm{HfZrO}_{4}$ at $250{ }^{\circ} \mathrm{C}$ and $\mathrm{Al}_{2} \mathrm{O}_{3}$ at $300{ }^{\circ} \mathrm{C} .{ }^{41,42}$ Using $\mathrm{HF}$ as the fluorinating agent and $\mathrm{TiCl}_{4}$ as the ligand-exchange agent, the etch rate for amorphous $\mathrm{HfO}_{2}$ was 18 times higher than the etch rate for crystalline $\mathrm{HfO}_{2} .^{41}$ Using the same reagents, the etch rate for amorphous $\mathrm{ZrO}_{2}$ was 2.3 times higher than the etch rate for crystalline $\mathrm{ZrO}_{2}{ }^{41}$ Similarly using $\mathrm{HF}$ and dimethyl aluminium chloride (DMAC, $\left.\mathrm{Al}\left(\mathrm{CH}_{3}\right)_{2} \mathrm{Cl}\right)$ the etch rate on amorphous $\mathrm{HfO}_{2}$ was 8.5 times higher than the etch rate on crystalline $\mathrm{HfO}_{2}$, whereas for $\mathrm{ZrO}_{2}$ the amorphous etch rate was 1.4 times higher than the crystalline etch rate. ${ }^{41}$ This shows for $\mathrm{HfO}_{2}$ that the etch rates is strongly dependent on whether a crystalline or amorphous film is etched. ${ }^{41}$ Amorphous materials have a lower density than their crystalline form, which may facilitate the fluorination that leads to an expansion of the metal oxide. ${ }^{41}$ In wet $\mathrm{HF}$ etching, crystalline $\mathrm{HfO}_{2}$ is also etched more slowly than amorphous $\mathrm{HfO}_{2} \cdot{ }^{43}$ The differences in etch rates show potential for selective ALE where two different materials have different etch rates under the same conditions. $^{41}$

Given that it is difficult to investigate thermal ALE reactions directly using experimental techniques, first-principles based atomic-level simulations using density functional theory (DFT) can give deep insights into the precursor chemistry and the reactions that drive the etch of metal oxides. Our previous study examined the difference 
in thermal ALE for the fluorination step for crystalline $\mathrm{HfO}_{2}$ and $\mathrm{ZrO}_{2}$ using $\mathrm{HF}^{4}{ }^{44}$ In the present paper, the HF pulse in the first step in thermal ALE of amorphous $\mathrm{HfO}_{2}$ is examined in detail with first-principles DFT calculations of the fluorination mechanism. HF molecules adsorb at the surfaces of metal oxides by forming metal-F bonds and they may remain intact or dissociate. ${ }^{45}$ If $\mathrm{HF}$ dissociates it may form $\mathrm{Hf}-\mathrm{F}$ and $\mathrm{O}-\mathrm{H}$ bonds, and release water, similar to previous studies on etch modelling for crystalline $\mathrm{HfO}_{2}, \mathrm{ZrO}_{2}$ and $\mathrm{Al}_{2} \mathrm{O}_{3} .{ }^{44,45}$ The amount etched (etch rate) is determined by how much of the oxide surface is fluorinated; a larger fluoride film thickness after fluorination can lead to more fluoride removed during the ligand-exchange step and high etch rates. ${ }^{41}$

The Natarajan-Elliott analysis ${ }^{44}(\mathrm{~N}-\mathrm{E})$ is used to predict the conditions at which a self-limiting (SL) or spontaneous etching (SE) reaction becomes thermodynamically favourable and can therefore be used to direct experimental studies of thermal ALE. Selflimiting reactions are a necessary part of thermal ALE and allow the degree of etching to be well controlled and defined. In this study, it is found that SL reactions are more favourable than the competing SE reaction for the $\mathrm{HF}$ pulse on amorphous $\mathrm{HfO}_{2}$ at 0 and $520 \mathrm{~K}$; the latter corresponds to the temperature used in experimental studies of thermal ALE for $\mathrm{HfO}_{2}$ using $\mathrm{HF}$ as the fluorination agent ${ }^{46}$. The temperatures above which spontaneous etching is favoured range from 718 to $1302 \mathrm{~K}$ at typical thermal ALE reactant pressures, depending on the degree of fluorination; these are significantly higher than on crystalline $\mathrm{HfO}_{2}$. Introducing $\mathrm{HF}$ molecules to the amorphous $\mathrm{HfO}_{2}$ surface results in dissociative HF adsorption. The maximum coverage of Hf-F bonds on the surface is used to calculate a theoretical etch rate. The spontaneous formation of water and hydrogen peroxide is also discussed. Combining the thermodynamic and mechanistic investigation 
using first-principles simulation demonstrates the origin of the large difference in etch rates for crystalline and amorphous $\mathrm{HfO}_{2}$ allowing the design of novel ALE processes for other technologically relevant materials.

\section{Computational Methods}

All calculations reported in this paper were carried out using spin-polarized density functional theory implemented in VASP ${ }^{47}$ 5.4. The Perdew-Burke-Ernzerhof (PBE) generalized gradient approximation (GGA) to exchange-correlation (XC) functional is used. ${ }^{48}$ The convergence criteria for total energies and the forces for ionic relaxation are 1 x $10^{4} \mathrm{eV}$ and $2 \times 10^{-2} \mathrm{eV} / \AA ̊ \AA$ respectively. The Methfessel-Paxton first order smearing method is used with a broadening of $0.1 \mathrm{eV}$ for the electronic relaxations. The core-valance electron interactions are represented by projector-augmented wave (PAW) potentials, ${ }^{49}$ and the following valence electron configurations are used: Hf: $6 s^{2} 5 d^{2}, O: 2 s^{2} 2 p^{4}, F: 2 s^{2} 2 p^{5}$, and $\mathrm{H}: 1 \mathrm{~s}^{1}$. The valence electrons are described with a periodic plane-wave basis set using a kinetic energy cutoff of $400 \mathrm{eV}$.

The Gibbs free energy, $\Delta \mathrm{G}$, at a temperature, $\mathrm{T}$, is computed as follows:

$$
\begin{gathered}
\Delta G=\Delta H-T \Delta S+R T \ln (Q) \\
\Delta H=\Delta E+\Delta Z P E+\Delta W(T) \\
\Delta E=\sum_{p} \mu E_{p}-\sum_{r} \mu E_{r} \\
Q=\prod p_{\text {products }}^{\mu} / \prod p_{\text {reactants }}^{\mu}
\end{gathered}
$$


The $\Delta \mathrm{H}$ and $\Delta \mathrm{S}$ terms in Eq. (1) are the changes in reaction enthalpy and reaction entropy respectively, with term $\mathrm{RT} \ln (\mathrm{Q})$ included since the partial pressures of the reactants and products are variable in the reaction chamber. In Eq. (2), $\Delta H$ contains the electronic reaction energy at $0 \mathrm{~K} \Delta \mathrm{E}$, zero-point energy change $\Delta \mathrm{ZPE}$ and a temperaturedependent enthalpy change $\Delta \mathrm{W}(\mathrm{T})$. The stoichiometric coefficient of the corresponding species is $\mu$ and the reactant and product species are $r$ and $p$ respectively in Eq. (3). A reactant pressure of 0.2 Torr and a product pressure of 0.01 Torr are used for the free energy calculations. Of course, it is not possible to control the product pressure in an etch reactor. It is however, lower than the reactant pressure, so a value of 0.01 Torr for our calculations is consistent with this and previous work of DFT investigation in thermal etching of TiN. ${ }^{50}$

\section{A. Bulk and Slab Models}

Bulk amorphous $\mathrm{HfO}_{2}$ (henceforth $\mathrm{aHfO}_{2}$ ) was prepared using classical molecular dynamics (MD) simulations with the LAMMPS package. ${ }^{51}$ Atomic pair interactions were adopted from the Morse type potential developed by Broglia et al. ${ }^{52}$ This potential is accurate for the simulation of glasses at high temperature and pressure and has been previously used for the study of $\mathrm{aHfO}_{2} .{ }^{52}$ The Nosé-Hoover thermostat in its isothermalisobaric form (NPT) was used to set the constant pressure at $1 \mathrm{~atm}$ and the temperatures during the simulation. The integration time step was set to $0.1 \mathrm{fs}$. The amorphous structure was produced using the melt-quenching method. Initially, a total of 216 atoms with a stoichiometric $\mathrm{HfO}_{2}$ composition (72 $\mathrm{Hf}$ and $144 \mathrm{O}$ atoms) are randomly placed in a periodic cubic box. After an initial equilibration, the system is warmed up to $4000 \mathrm{~K}$ at a rate of $10 \mathrm{~K} / \mathrm{ps}$. The temperature was set well above the experimental melting point and 
equilibrated for $2 \mathrm{~ns}$ to assure the initially random distribution of the atomic species in our model. The melted structure is then quenched to $300 \mathrm{~K}$ in consecutive steps of $10 \mathrm{~K} / \mathrm{ps}$ (i.e. every $10^{4}$ time-steps) and finally equilibrated for $1 \mathrm{~ns}$ at room conditions. The quenching rate was chosen to be quick enough to produce an amorphous structure at equilibrium; a pair distribution function is shown in Section 1 of the supplementary material. This procedure leads to an equilibrated cubic box with side dimensions of $13.72 \AA$. The density of the resulting simulation box is $9.62 \mathrm{~g} / \mathrm{cm}^{3}$, which is in good agreement with other $\mathrm{aHfO}_{2}$ models generated by MD. ${ }^{53-55}$ The surface model is cleaved from the bulk at a plane parallel to one of the box sides, where a large vacuum layer is introduced. To moderate the likely abundance of uncoordinated species at the surface formed from a random cleavage of the amorphous bulk, a rapid melt-quenching was run for the slab model keeping constant volume and temperature (NVT ensemble). The surface model was warmed to $4000 \mathrm{~K}$ at 20 $\mathrm{K} / \mathrm{ps}$ rate, relaxed for $50 \mathrm{ps}$, quenched to $300 \mathrm{~K}$ at $10 \mathrm{~K} / \mathrm{ps}$ rate, and finally equilibrated for $1 \mathrm{~ns}$. The slab model is then relaxed using DFT.

The $\mathrm{aHfO}_{2}$ bulk was relaxed by simultaneous relaxation of the ionic positions, cell volume and cell with an energy cutoff of $550 \mathrm{eV}$ and a Monkhorst-Pack k-point sampling mesh of $(1 \times 1 \times 1)$. The bulk $\mathrm{aHfO}_{2}$ has $72 \mathrm{Hf}$ and $144 \mathrm{O}$ atoms and the optimized lattice constants are $\mathrm{a}=13.729 \AA \mathrm{A}, \mathrm{b}=13.871 \AA$ and $\mathrm{c}=13.796 \AA$ and angles alpha $=90.74^{\circ}$, beta $=89.14^{\circ}$ and gamma $=89.81^{\circ}$. The density of our bulk aHfO 2 model is $9.62 \mathrm{~g} / \mathrm{cm}^{3}$ which is smaller than the crystalline $\mathrm{HfO}_{2}\left(\right.$ monoclinic, $\left.\mathrm{cHfO}_{2}\right)$ density from our previous study which was $10.01 \mathrm{~g} / \mathrm{cm}^{3} .44$ The surface slab of $\mathrm{aHfO}_{2}$ with $16 \AA$ of vacuum separating the slabs is used for the surface models with a stoichiometry of $\mathrm{Hf}_{72} \mathrm{O}_{144}$ per supercell. A kpoint sampling mesh of $(2 \times 2 \times 1)$ is used for geometry optimization. 
For the N-E analysis, the self-limiting reaction product state models are obtained by replacing every oxygen removed from the surface of the slab model with two fluorine atoms, this ratio is shown as $1 \mathrm{O} / 2 \mathrm{~F} .{ }^{44}$ Three self-limiting product state models: $8 \mathrm{O} / 16 \mathrm{~F}$, $10 \mathrm{O} / 20 \mathrm{~F}$ and $16 \mathrm{O} / 32 \mathrm{~F}$ are examined. Enthalpy $\mathrm{H}$ and entropy $\mathrm{S}$ are computed using the Phonopy ${ }^{56}$ code for only the top layers of fluorinated Hf atoms for the surface calculations For the gas phase molecules, $\mathrm{H}$ and $\mathrm{S}$ were calculated from the freeh program in the Turbomole ${ }^{57,58}$ suite at 1 atm pressure using the PBE exchange-correlation functional ${ }^{48}$ and a polarized triple basis set (def-TZVPP) $)^{59,60}$ and default medium grid. The reactant molecules and gas-phase byproducts calculations are performed in VASP with a large periodic box of dimensions $15.0 \AA$ x $16.0 \AA$ x $15.5 \AA$ and $400 \mathrm{eV}$ plane-wave energy cutoff.

Experimental studies have shown that the chemical composition of $\mathrm{aHfO}_{2}$ is essentially stoichiometric. ${ }^{61}$ Theoretical studies of $\mathrm{aHfO}_{2}$ reported that the coordination numbers for the Hf atoms were five, six, seven and eight with a preference for six and seven. For oxygen two, three and four coordination are found, with a preference for three and four coordination. ${ }^{53}$ The distribution of the coordination numbers for the $\mathrm{Hf}$ and $\mathrm{O}$ atoms of the bulk aHfO $\mathrm{H}_{2}$ model used in this study is shown in Figure 2. To determine the coordination number, a cutoff radius of $2.50 \AA$ derived from the behaviour of $\mathrm{Hf}-\mathrm{O}$ bonds is used. ${ }^{62}$ Three-coordinated $\mathrm{O}$ atoms and six-coordinated/seven-coordinated Hf atoms dominate the bulk $\mathrm{aHfO}_{2}$ model which agrees with previous classical ${ }^{63}$ and ab initio ${ }^{64,65}$ molecular dynamic studies. Compared to the monoclinic phase, the coordination number for the $\mathrm{Hf}$ atoms can be seven or eightfold, and the $\mathrm{O}$ atoms can be either three or fourfold coordinated. ${ }^{61}$ 


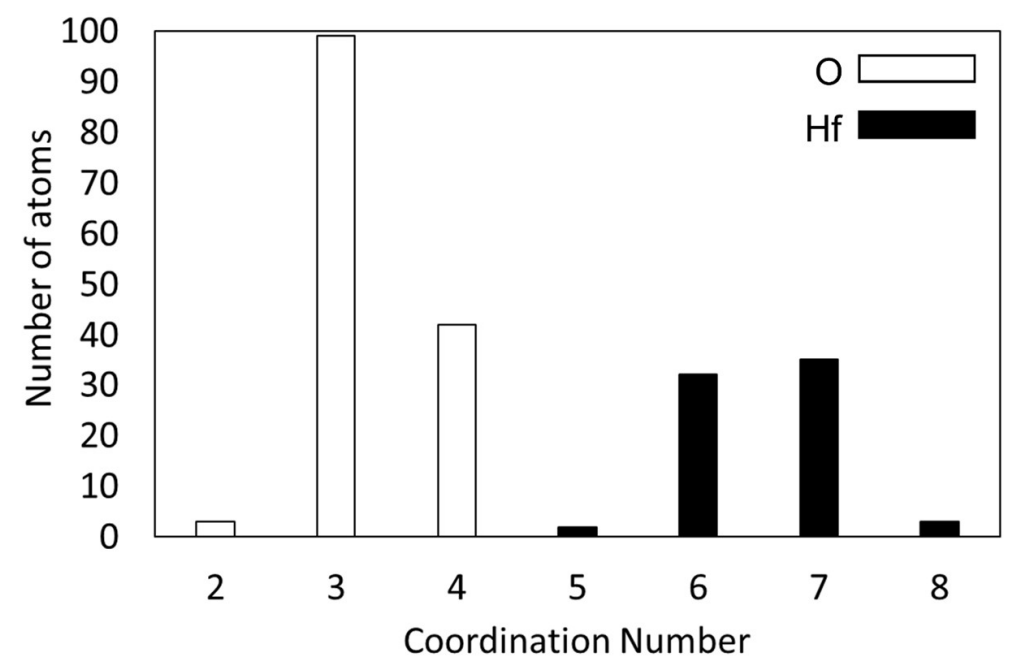

Figure 2. Distribution of coordination numbers for the bulk $\mathrm{aHfO}_{2}$ model used in this study that was prepared using classical molecular dynamics.

\section{RESULTS AND DISCUSSION}

\section{A. Self-Limiting vs Spontaneous Etch}

To predict if the HF pulse will promote spontaneous etch (SE) or a self-limiting (SL) reaction on $\mathrm{aHfO}_{2}$, the energetics and thermodynamics at given conditions are compared. Table $I$ shows two possible SE and two possible SL reactions for the HF pulse on $\mathrm{aHfO}_{2}$ as well as the reaction (free) energies at $0 \mathrm{~K}$ and at a typical thermal ALE temperature of $520 \mathrm{~K}$ and the computed minimum barrier to spontaneous etching. A negative minimum barrier would indicate that spontaneous etching is thermodynamically favourable and is prevented only by potential kinetic barriers. 
Table I. Reaction energies at $0 \mathrm{~K}(\Delta \mathrm{E})$ and free energies at $520 \mathrm{~K}(\Delta \mathrm{G})$ from the model SE and SL reactions after the $\mathrm{HF}$ pulse on $\mathrm{aHfO}_{2}$. For this table, the product state is $8 \mathrm{O} / 16 \mathrm{~F}$ and the numbers in parenthesis are the minimum barriers to continuous etching.

\begin{tabular}{llcc} 
& Reactions & $\Delta \mathrm{E}(\mathrm{eV} / \mathrm{M})$ & $\Delta \mathrm{G}(\mathrm{eV} / \mathrm{M})$ \\
\hline $\mathrm{SE} 1$ & $1 \mathrm{HfO}_{2(\mathrm{~b})}+4 \mathrm{HF}_{(\mathrm{g})} \rightarrow 1 \mathrm{HfF}_{4(\mathrm{~g})}+2 \mathrm{H}_{2} \mathrm{O}_{(\mathrm{g})}$ & -1.44 & -1.15 \\
$\mathrm{SL} 1$ & $1 \mathrm{HfO}_{2(\text { surface })}+4 \mathrm{HF}_{(\mathrm{g})} \rightarrow 1 \mathrm{HfF}_{4(\text { surface })}+2 \mathrm{H}_{2} \mathrm{O}_{(\mathrm{g})}$ & $-4.07(2.63)$ & $-1.87(0.72)$ \\
$\mathrm{SE} 2$ & $1 \mathrm{HfO}_{2(\mathrm{~b})}+2 \mathrm{HF}_{(\mathrm{g})} \rightarrow 1 \mathrm{HfOF}_{2(\mathrm{~g})}+1 \mathrm{H}_{2} \mathrm{O}_{(\mathrm{g})}$ & 3.35 & 2.58 \\
$\mathrm{SL} 2$ & $1 \mathrm{HfO}_{2 \text { (surface) }}+2 \mathrm{HF}_{(\mathrm{g})} \rightarrow 1 \mathrm{HfOF}_{2 \text { (surface) }}+1 \mathrm{H}_{2} \mathrm{O}_{(\mathrm{g})}$ & $-2.04(5.39)$ & $-0.94(3.52)$
\end{tabular}

The SE1 and SE2 reactions convert the bulk $\mathrm{aHfO}_{2}$ into a volatile metal fluoride or metal oxyfluoride, respectively, and water. In reaction SE1, four HF molecules are required to etch one unit of bulk $\mathrm{HfO}_{2}$ forming $\mathrm{HfF}_{4}$ and water. In reaction SE2, two $\mathrm{HF}$ molecules are needed to etch one unit of $\mathrm{HfO}_{2}$ to form $\mathrm{HfOF}_{2}$ and $\mathrm{H}_{2} \mathrm{O}$. In both $\mathrm{SE}$ reactions, the surface of the material before and after each precursor pulse is identical and therefore their contributions are not required in these models.

The SL1 and SL2 reactions involve the conversion of the outermost surface layer of $\mathrm{aHfO}_{2}$ into the nonvolatile metal fluoride and nonvolatile metal oxyfluoride respectively with the release of water molecules. The SL product state of the surface is $8 \mathrm{O} / 16 \mathrm{~F}$ where eight oxygen were removed and replaced by sixteen fluorine. For both SL reactions, the surfaces are not identical before and after the pulse and their contributions have to be included. A negative free energy means that the corresponding reaction is exergonic (favourable), while a positive free energy means that the corresponding reaction is endergonic (unfavourable). At 0 and $520 \mathrm{~K}$, the SE1 reaction is favourable whereas the 
SE2 reaction is unfavorable. Table I shows that the barrier to spontaneous etch is positive for all the SE and SL reactions at $0 \mathrm{~K}$, indicating that the self-limiting reaction is most favourable energetically and at $520 \mathrm{~K}$ this barrier to spontaneous etching, although reduced, remains positive. Therefore, up to $520 \mathrm{~K}$, the reactions with $\mathrm{HF}$ in the first step will be preferentially self-limiting on aHfO 2 , similar to crystalline $\mathrm{HfO}_{2}$.

Only the SE1 reaction is considered for further analysis, as the SE2 reaction is unfavorable at 0 and $520 \mathrm{~K}$ and the SL2 reaction is less favorable than the SL1 reaction at 0 and $520 \mathrm{~K}$. In addition, the high barrier to etch for the SL2 and SE2 reactions suggests that spontaneous formation of the metal oxyfluoride is not likely at ALE-relevant temperatures around $520 \mathrm{~K}$. The reaction free energy profiles (FEPs) of the SE1 and SL1 reactions are shown in Figure 3 and at a given temperature and reactant pressure these show whether spontaneous etching or self-limited conversion of $\mathrm{aHfO}_{2}$ into a nonvolatile metal fluoride layer are preferred. A reactant pressure of 0.2 Torr and a product pressure of 0.01 Torr are used and the temperature range is $0-1000 \mathrm{~K}$. 


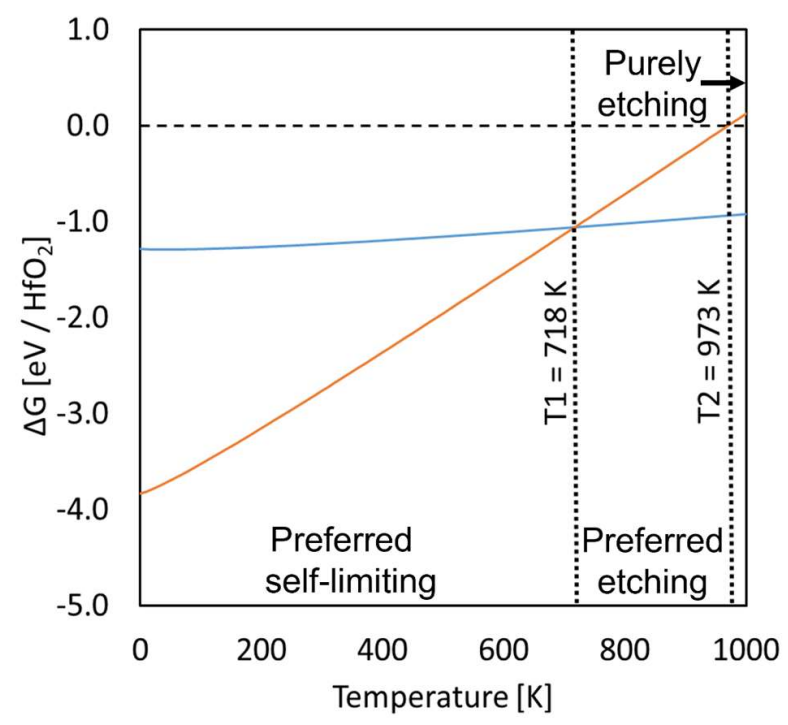

Figure 3. Free energy profile for the SE1 (blue) and SL1 (orange) reactions of $\mathrm{aHfO}_{2}$ from 0 to $1000 \mathrm{~K}$ at the pressures given in the text. T1 is where the SL and SE reactions cross over for the $8 \mathrm{O} / 16 \mathrm{~F}$ model, and $\mathrm{T} 2$ is where spontaneous etching is preferred.

In Figure 3 the self-limiting reaction is preferred up to $717 \mathrm{~K}$, at $718 \mathrm{~K}$ the minimum barrier to etch is zero with SE1 and SL1 being isoenergetic and at temperatures higher than $718 \mathrm{~K}$ spontaneous etching becomes more favourable. At $973 \mathrm{~K}$, the self-limiting reaction becomes unfavourable while spontaneous etching remains favourable. Surface hafnium atoms are easier to remove in the ligand-exchange step when more oxygen atoms are removed due to the reduced hafnium-oxygen bonds interaction. The surface of $\mathrm{aHfO}_{2}$ has 19 oxygen atoms in the supercell that could react with the HF molecules, therefore we study the FEPs for two other SL product models, 10O/20F (SL2) and 16O/32F (SL3) as shown in Table $I I$ and Figure 4 to compare their thermodynamic stability with the $8 \mathrm{O} / 16 \mathrm{~F}$ model. For the 10O/20F model, 10 of the surface oxygen are removed and 20 fluorine are added to replace them. For the 16O/32F, 16 oxygen are removed and 32 fluorine are added to replace them. All three SL product states are more favourable than the SE reaction at 0 
and $520 \mathrm{~K}$ with positive minimum barriers as shown in Table II. Experimental work showed that the $\mathrm{HF}$ reaction is self-limiting on amorphous $\mathrm{HfO}_{2}$ at $250{ }^{\circ} \mathrm{C}(523 \mathrm{~K}) \cdot{ }^{41}$ Figure 4 shows that the self-limiting product state models are more favourable than the spontaneous etch reaction at $523 \mathrm{~K}$ with the $16 \mathrm{O} / 32 \mathrm{~F}$ (SL3) being favourable up to 1302 $\mathrm{K}$.

Table II. Reaction (free) energies and minimum barriers at 0 and $520 \mathrm{~K}$ for the model selflimiting for $8 \mathrm{O} / 16 \mathrm{~F}, 10 \mathrm{O} / 20 \mathrm{~F}$ and $16 \mathrm{O} / 32 \mathrm{~F} \mathrm{SL}$ product states.

\begin{tabular}{cccc} 
& SL Product State & $\Delta \mathrm{E}(0 \mathrm{~K})(\mathrm{eV} / \mathrm{M})$ & $\Delta \mathrm{G}(520 \mathrm{~K})(\mathrm{eV} / \mathrm{M})$ \\
\hline $\mathrm{SE} 1$ & $\mathrm{HfF}_{4}$ & -1.44 & -1.15 \\
$\mathrm{SL} 1$ & $8 \mathrm{O} / 16 \mathrm{~F}$ & $-4.07(2.63)$ & $-1.87(0.72)$ \\
$\mathrm{SL} 2$ & $10 \mathrm{O} / 20 \mathrm{~F}$ & $-4.02(2.58)$ & $-1.97(0.82)$ \\
$\mathrm{SL} 3$ & $16 \mathrm{O} / 32 \mathrm{~F}$ & $-5.51(4.07)$ & $-3.48(2.33)$ \\
\hline
\end{tabular}




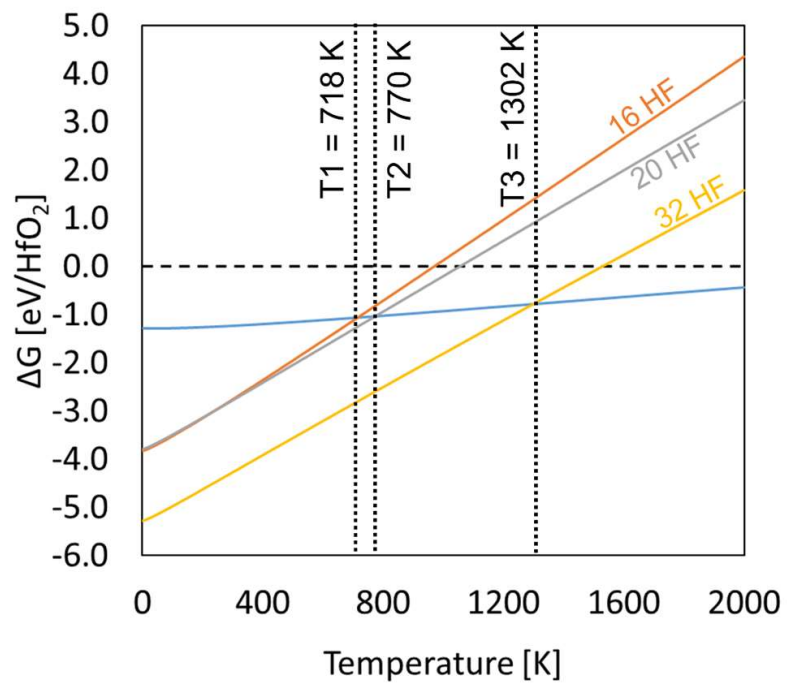

Figure 4. Free energy profiles of the spontaneous etching and self-limiting reactions for $\mathrm{aHfO}_{2} . \mathrm{T} 1, \mathrm{~T} 2$ and $\mathrm{T} 3$ are the temperatures where the self-limiting and spontaneous etch reactions cross over for $8 \mathrm{O} / 16 \mathrm{~F}, 10 \mathrm{O} / 20 \mathrm{~F}$ and $16 \mathrm{O} / 32 \mathrm{~F}$ models respectively.

\section{B. Adsorption of one $\mathrm{HF}$ to the bare amorphous $\mathrm{HfO}_{2}$ surface}

One HF molecule was adsorbed at the bare surface of $\mathrm{aHfO}_{2}$ on different binding sites (labelled A, B and C) that were chosen at random as typical binding sites. At each binding site the $\mathrm{HF}$ molecule spontaneously dissociated to form $\mathrm{Hf}-\mathrm{F}$ and $\mathrm{O}-\mathrm{H}$ bonds as shown in Figure 5. Similar to the crystalline $\mathrm{HfO}_{2}$ and $\mathrm{ZrO}_{2}{ }^{44}, \mathrm{HF}$ dissociation proceeds after a stable metal-fluorine bond is formed. The $\mathrm{Hf}-\mathrm{F}$ and $\mathrm{O}-\mathrm{H}$ bond lengths are shown for each binding site in Figure 5. The computed adsorption energies for the dissociative adsorption of one $\mathrm{HF}$ molecule on the bare surface of $\mathrm{aHfO}_{2}$ are $-2.17,-2.92$, and -2.00 $\mathrm{eV}$ at sites $\mathrm{A}, \mathrm{B}$, and $\mathrm{C}$, respectively. These adsorption energies are more negative than on $\mathrm{cHfO}_{2}$, most likely as a result of the surface disorder and range of coordination numbers of the surface atoms. This indicates that the fluorination steps in thermal self-limiting etch of 
$\mathrm{aHfO}_{2}$ would proceed faster than on $\mathrm{cHfO}_{2}$. The surface $\mathrm{O}$ atoms are 1-fold, 2-fold or 3fold coordinated by surface Hf atoms with the 3 -fold being dominant in the model used in this study. The surface Hf atoms are 5-fold, 6-fold or 7-fold coordinated by surface $\mathrm{O}$ atoms with the 6-fold being dominant in the model used in this study. The lower coordination numbers in $\mathrm{aHfO}_{2}$ promote the interaction with $\mathrm{HF}$ and metal fluorination.

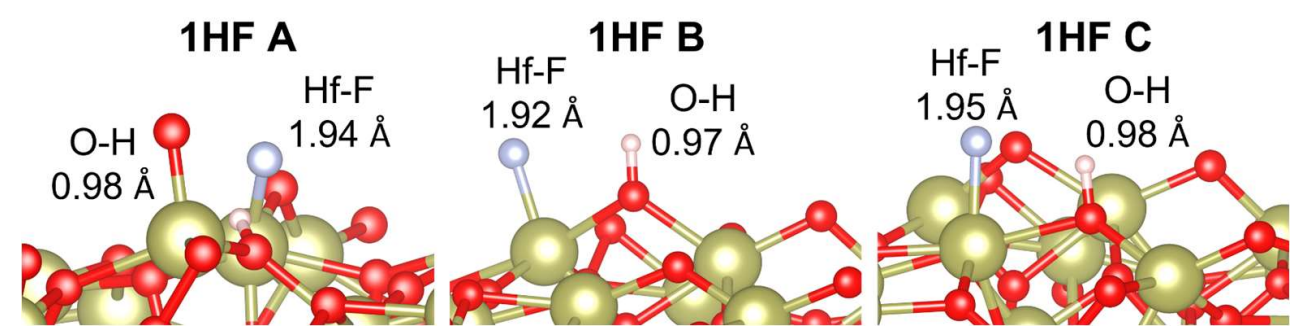

Figure 5. Relaxed adsorption structures for one HF molecule interacting with the bare surface of $\mathrm{aHfO}_{2}$. The colour coding is brown $=\mathrm{Hf}$, red $=\mathrm{O}$, white $=\mathrm{H}$ and blue $=\mathrm{F}$.

\section{Stability of Higher HF Coverages}

Similar to our previous study on crystalline $\mathrm{HfO}_{2}$ and $\mathrm{ZrO}_{2}$, higher $\mathrm{HF}$ coverages were examined by introducing up to 34 randomly oriented HF molecules per supercell approximately $3 \AA$ from the bare surface of $\mathrm{aHfO}_{2}$. This was studied to see if higher HF coverages would result in complete dissociation or a mixture of molecular and dissociative adsorption of the HF molecules. There are 18 topmost hafnium atoms on the surface of the supercell that may form $\mathrm{Hf}-\mathrm{F}$ bonds and 19 surface oxygen atoms that can form $\mathrm{O}-\mathrm{H}$ bonds or as seen in some cases $\mathrm{H}_{2} \mathrm{O}$ and $\mathrm{H}_{2} \mathrm{O}_{2}$. For $\mathrm{HF}$ coverages using 2, 3, 4, 5, and 8 molecules per supercell three different configurations (labelled A, B and C) were used, for the $16 \mathrm{HF}$ coverages two configurations (A and $\mathrm{B}$ ) were used and one configuration for HF coverages of 28, 30, 32 and 34 molecules per supercell. Some configurations from HF coverages of 2, 3, 4 and $5 \mathrm{HF}$ resulted in spontaneous complete dissociation of the adsorbed 
HF molecules as shown in Figure 6. There was a mixture of molecular and dissociative adsorption of the HF molecules in all other HF adsorption configurations (see Section 2 of the supplementary material for their geometries). The molecular adsorbed HF molecules are likely to remain bonded to the surface in the next ALE step as they form strong bonds (Hf-F $6.7 \mathrm{eV})^{66}$ and would likely dissociate when the kinetic barriers are reduced in the reactor during the ALE process. Similar to our previous study ${ }^{44}$ on crystalline $\mathrm{HfO}_{2}$, the HF molecules that did not dissociate in the relaxed geometries form hydrogen bonds with the remaining HF molecules and dissociated $\mathrm{F}$ atoms and at higher HF coverages a more extensive hydrogen-bonded network is expected.

2HF B

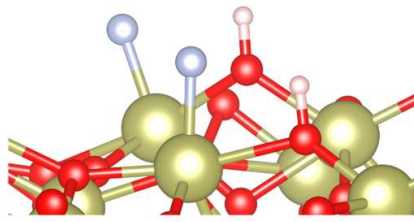

3HF C

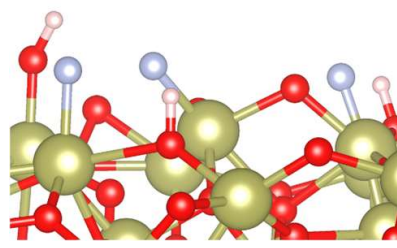

2HF C

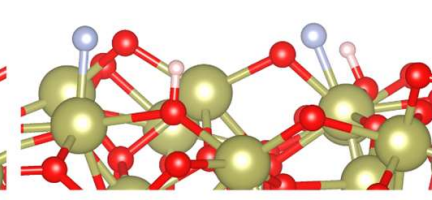

4HF B
3HF B

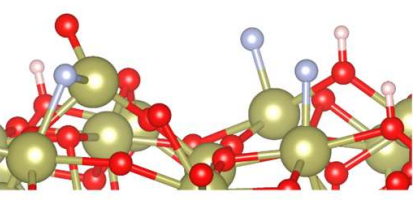

5HF A

Figure 6. Relaxed geometries for HF coverages 2HF B, 2HF C, 3HF B, 3HF C, 4HF B and 5HF A of amorphous $\mathrm{HfO}_{2}$ where complete dissociation of $\mathrm{HF}$ occurred spontaneously. Colour coding is the same as in Figure 5.

The binding energies per HF and per unit surface area of the material were computed as shown in Table III. As the number of Hf-F bonds increases on the bare $\mathrm{aHfO}_{2}$ surface with higher HF coverages, the binding energy per surface area becomes more 
favourable as shown in Table III and Figure 7(c) with Hf-F coverage from $1.1 \pm 0.3$ to 9.0 $\pm 0.3 \mathrm{HF} / \mathrm{nm}^{2}$ with surface binding energies -5.3 to $-20.0 \mathrm{eV} / \mathrm{nm}^{2}$ (see Section 3 of the supplementary material for the error bar explanation).

Table III. Adsorbate coverages and binding energies for the $\mathrm{HF}$ coverages on $\mathrm{aHfO}_{2}$.

\begin{tabular}{llcccc} 
Geometry & $\begin{array}{l}\text { Adsorbed } \\
\left(\mathrm{nm}^{-2}\right)\end{array}$ & $\begin{array}{c}\mathrm{HF}-\mathrm{F} \\
\left(\mathrm{nm}^{-2}\right)\end{array}$ & Dissociated $\mathrm{HF}\left(\mathrm{nm}^{-2}\right)$ & $\begin{array}{c}\text { Ebind } \\
(\mathrm{eV} / \mathrm{HF})\end{array}$ & Ebind $\left(\mathrm{eV} / \mathrm{nm}^{2}\right)$ \\
\hline 2HF A & 1.1 & 0.5 & 0.5 & -1.3 & -1.4 \\
2HF B & 1.1 & 1.1 & 1.1 & -2.2 & -2.4 \\
2HF C & 1.1 & 1.1 & 1.1 & -5.0 & -5.3 \\
3HF A & 1.6 & 1.1 & 1.1 & -1.7 & -2.7 \\
3HF B & 1.6 & 1.6 & 1.6 & -1.7 & -2.8 \\
3HF C & 1.6 & 1.6 & 1.6 & -2.3 & -3.6 \\
4HFA & 2.1 & 1.6 & 1.6 & -3.4 & -7.2 \\
4HFB & 2.1 & 2.1 & 2.1 & -1.8 & -3.8 \\
4HFC & 2.1 & 1.6 & 1.6 & -1.9 & -3.9 \\
5HFA & 2.7 & 2.7 & 2.7 & -3.4 & -8.9 \\
5HFB & 2.7 & 2.7 & 2.7 & -3.1 & -8.1 \\
5HFC & 2.7 & 2.1 & 2.1 & -1.7 & -4.4 \\
8HFA & 4.2 & 3.7 & 3.2 & -1.6 & -6.6 \\
8HFB & 4.2 & 3.7 & 3.2 & -1.6 & -6.7 \\
8HFC & 4.2 & 3.2 & 2.7 & -2.2 & -9.4 \\
16HFA & 8.5 & 6.4 & 5.3 & -1.7 & -14.6 \\
16HFB & 8.5 & 3.7 & 6.4 & -1.2 & -9.9 \\
28HF & 14.8 & 5.3 & -1.2 & -17.7 \\
30HF & 15.9 & 2.7 & -1.1 & -17.9 \\
\hline \hline
\end{tabular}




\begin{tabular}{llllll}
\hline $32 \mathrm{HF}$ & 16.7 & 9.0 & 8.0 & -1.2 & -19.8 \\
$34 \mathrm{HF}$ & 18.0 & 9.0 & 8.0 & -1.1 & -20.0 \\
\hline \hline
\end{tabular}
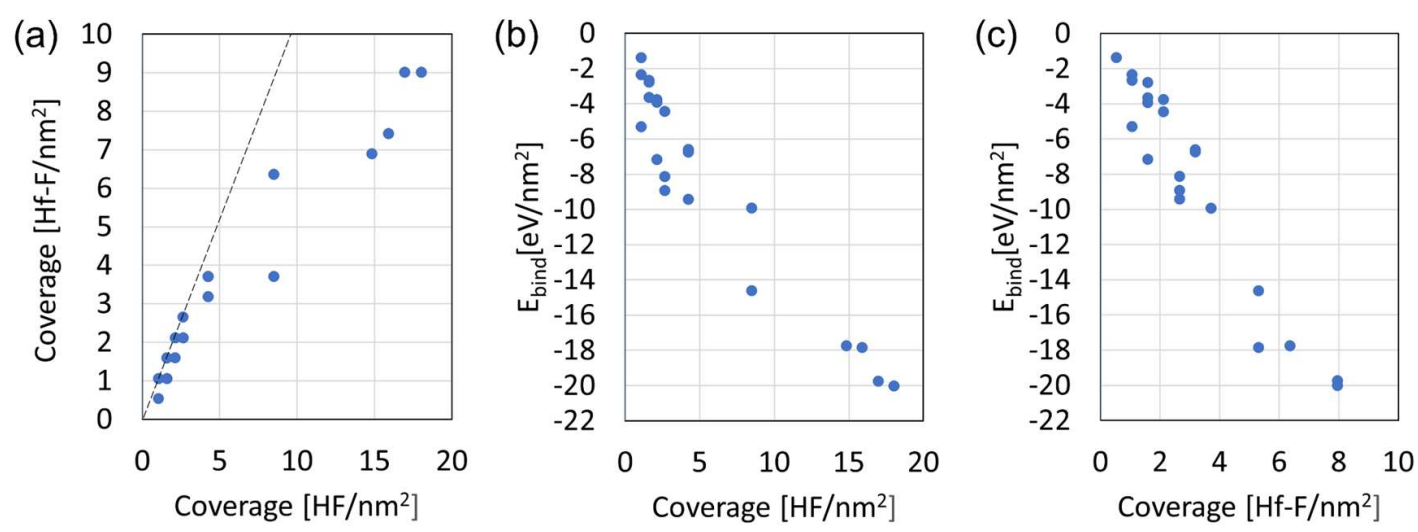

Figure 7 (a) Scatter plot for Hf-F coverage versus total HF coverage for the surface coverage values in Table III. Plots (b) and (c) show the change in binding energy per square nanometer with an increase in HF and Hf-F coverage, respectively.

Hf-F coverage versus adsorbed HF coverage is shown in plot (a) in Figure 7 with the HF coverages that resulted in complete dissociation lying along the correlation line. This corresponds to coverages of $1.1,1.6,2.1$ and $2.7 \mathrm{HF} / \mathrm{nm}^{2}$. The remaining data points are HF coverages that correspond to geometries where partially dissociated HF and molecular adsorbed HF molecules are present and therefore lie below the correlation line. The Hf-F coverage starts to plateau at higher HF coverages suggesting a maximum coverage of $9.0 \pm 0.3 \mathrm{Hf}-\mathrm{F} / \mathrm{nm}^{2}$. Also note that the number of Hf-F/nm² is the same for HF coverages 32 and $34 \mathrm{HF}$. It is also shown that a saturation in the binding energy is not reached at high HF coverages and Hf-F coverages respectively as shown in plots (b) and 
(c) in Figure 7. We use the highest adsorbed HF coverage of 34 HF with Hf-F coverage of $9.0 \pm 0.3 \mathrm{Hf}-\mathrm{F} / \mathrm{nm}^{2}$ as the maximum coverage for the $\mathrm{aHfO}_{2}$ etch rate prediction.

\section{Spontaneous Formation of $\mathrm{H}_{2} \mathrm{O}$ and $\mathrm{H}_{2} \mathrm{O}_{2}$}

$\mathrm{H}_{2} \mathrm{O}$ spontaneously formed in some of the relaxed geometries such as $5 \mathrm{HF} \mathrm{C}, 8 \mathrm{HF}$ $\mathrm{C}$ and $16 \mathrm{HF}$ A as shown in Figure 8. The dissociation of at least two HF molecules provides the hydrogen atoms required to form $\mathrm{H}_{2} \mathrm{O}$ as a reaction product which removes oxygen from $\mathrm{aHfO}_{2}$ during ALE. The $\mathrm{H}-\mathrm{O}-\mathrm{H}$ bond angles were $103.5^{\circ}, 105.1^{\circ}$ and $108.0^{\circ}$ for $5 \mathrm{HF} \mathrm{C}, 8 \mathrm{HF} \mathrm{C}$ and $16 \mathrm{HF}$ A as shown in Figure 8. The energy to remove $\mathrm{H}_{2} \mathrm{O}$ (energy of desorption) from the fluorinated surfaces of 5HF C, 8HF C and $16 \mathrm{HF}$ A, as typical examples where water was formed, was calculated using Eq. (5).

$$
E_{\text {des }}=\left(E_{H f O_{2(\text { surf })} / H F_{(a d s)}}+E_{H_{2} O_{(g)}}\right)-\left(E_{H f O_{2(\text { surf })} / H F_{(a d s)} / H_{2} O_{(a d s)}}\right)
$$

The total energy of $\mathrm{HF}$ adsorbed on $\mathrm{aHfO}_{2}$ with the spontaneous $\mathrm{H}_{2} \mathrm{O}$ formed is represented by the term " $E_{H f O_{2(s u r f)}} / H F_{(a d s)} / H_{2} O_{(a d s)}$ ". $\mathrm{H}_{2} \mathrm{O}$ was removed from the fluorinated surface and the resulting geometry was relaxed. The term " $E_{H f O_{2(s u r f)} / H F_{(a d s)}}$ " is the total energy of $\mathrm{HF}$ adsorbed on $\mathrm{aHfO}_{2}$ after removing $\mathrm{H}_{2} \mathrm{O}$ from the surface and " $E_{\mathrm{H}_{2} \mathrm{O}_{(g)}}$ " is the energy of gas-phase $\mathrm{H}_{2} \mathrm{O}$ molecule. The desorption energies of $\mathrm{H}_{2} \mathrm{O}$ on geometries $5 \mathrm{HF}$ C, 8HF C and $16 \mathrm{HF}$ A are 1.97, 1.47 and $1.67 \mathrm{eV}$ respectively. With the high energy gain from HF adsorption at $\mathrm{aHfO}_{2}$, we expect facile water desorption once it is formed. 


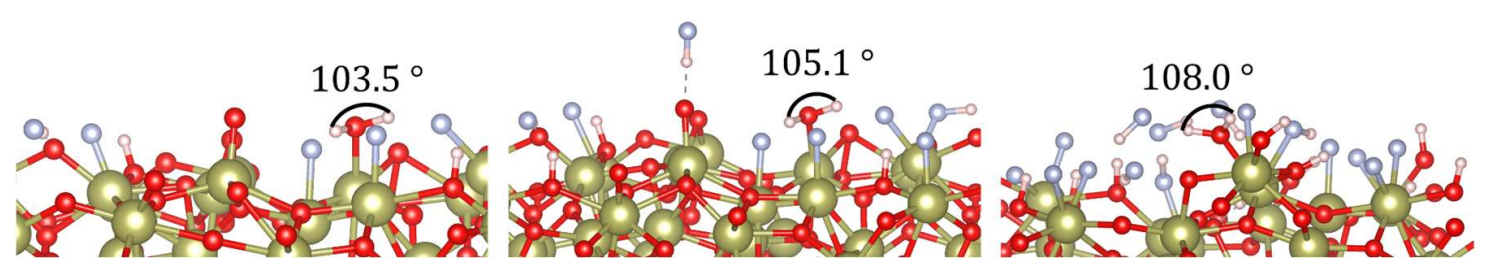

Figure 8. Relaxed geometries for $\mathrm{HF}$ coverages 5 HF C, $8 \mathrm{HF} \mathrm{C}$ and $16 \mathrm{HF}$ A where $\mathrm{H}_{2} \mathrm{O}$ formed spontaneously. Colour coding is the same as in Figure 5.

The spontaneous formation of $\mathrm{H}_{2} \mathrm{O}_{2}$ was also observed at higher $\mathrm{HF}$ coverages such as $28 \mathrm{HF}$ as shown in Figure 9. Similar to $\mathrm{H}_{2} \mathrm{O}$, the dissociation of at least two HF molecules provides the hydrogen atoms required to form $\mathrm{H}_{2} \mathrm{O}_{2}$ as a reaction product which removes oxygen from $\mathrm{aHfO}_{2}$. The $\mathrm{H}_{2} \mathrm{O}_{2}$ formed in Figure 9 had an $\mathrm{O}-\mathrm{O}$ bond length of $1.47 \AA$, O-H bond lengths of $1.05 \AA$ and $1.02 \AA$ and $\mathrm{H}-\mathrm{O}-\mathrm{O}$ bond angles $100.3^{\circ}$ and $104.5^{\circ}$. The energy to remove $\mathrm{H}_{2} \mathrm{O}_{2}$ (energy of desorption) from the fluorinated surface of $28 \mathrm{HF}$ was calculated using Eq. (5) where the " $\mathrm{H}_{2} \mathrm{O}$ " terms were replaced with " $\mathrm{H}_{2} \mathrm{O}_{2}$ ". The desorption energy was calculated to be $0.47 \mathrm{eV}$ which is low and can be achievable at process conditions to remove $\mathrm{H}_{2} \mathrm{O}_{2}$. Only the spontaneous formation of $\mathrm{H}_{2} \mathrm{O}$ was observed in our previous study of $\mathrm{HF}$ coverages on crystalline $\mathrm{HfO}_{2}$ and $\mathrm{ZrO}_{2} \cdot{ }^{44}$

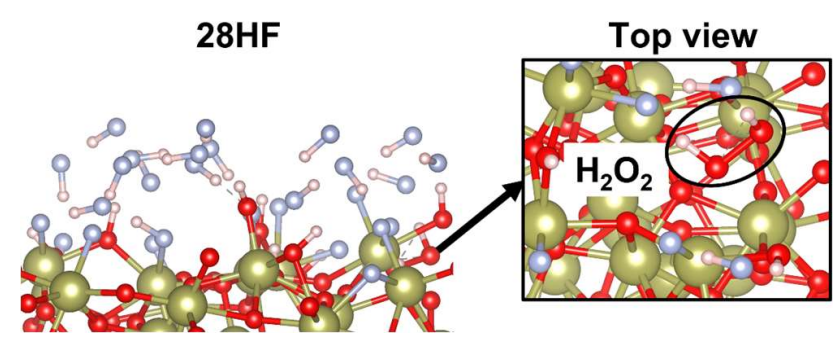

Figure 9. Relaxed geometry for $28 \mathrm{HF}$ where $\mathrm{H}_{2} \mathrm{O}_{2}$ formed spontaneously. Colour coding is the same as in Figure 5. 


\section{E. Discussion}

Comparing the spontaneous etch reaction to the self-limiting reaction for the $8 \mathrm{O} / 16 \mathrm{~F}$ SL product state model, at all temperatures less than $520 \mathrm{~K}$ using reactant and product pressures of 0.2 and 0.01 Torr respectively, the $\mathrm{HF}$ pulse on $\mathrm{aHfO}_{2}$ is self-limiting in nature as the reaction energies for the self-limiting reaction were more favourable than the spontaneous etch reaction. From this, it is suggested that the first precursor pulse using $\mathrm{HF}$ will produce a stable and non-volatile layer of metal fluorides and $\mathrm{H}_{2} \mathrm{O}$ or $\mathrm{H}_{2} \mathrm{O}_{2}$ as byproducts. The reaction energies for the SL product state models $8 \mathrm{O} / 16 \mathrm{~F}$ and $10 \mathrm{O} / 20 \mathrm{~F}$ were similar up to $400 \mathrm{~K}$ due to the small difference in the degree of fluorination between the models. The $16 \mathrm{O} / 32 \mathrm{~F}$ SL product state model reaction energies were more favourable than the $8 \mathrm{O} / 16 \mathrm{~F}$ and $10 \mathrm{O} / 20 \mathrm{~F}$ reactions up to $1302 \mathrm{~K}$. Comparing to our previous study examining the fluorination step of crystalline $\mathrm{HfO}_{2}$, the reaction energies for the $16 \mathrm{O} / 32 \mathrm{~F}$ product state model were less favourable than the partially fluorinated SL product state models. ${ }^{44}$ The greater the degree of fluorination on $\mathrm{aHfO}_{2}$, the more favourable the reaction energies are, showing $\mathrm{aHfO}_{2}$ favours higher fluorine content SL product states than less fluorinated SL product states, which will promote the self-limiting surface modification step. The replacement of oxygen with fluorine during fluorination may be easier due to the lower density of amorphous materials compared to crystalline materials. ${ }^{41}$

HF coverages on $\mathrm{aHfO}_{2}$ ranging from $1.1 \pm 0.3$ to $18.0 \pm 0.3 \mathrm{HF} / \mathrm{nm}^{2}$ resulted in complete dissociation or mixed dissociated and molecular HF adsorption. Water and hydrogen peroxide form spontaneously after relaxation and their computed desorption energies are low enough to be overcome at process conditions. A maximum coverage of $9.0 \pm 0.3 \mathrm{Hf}-\mathrm{F} / \mathrm{nm}^{2}$ was found at higher HF coverages to be used to calculate a theoretical 
etch rate. The surface area of the $\mathrm{aHfO}_{2}$ supercell is $1.88 \mathrm{~nm}^{2}$ with $18 \mathrm{Hf}$ atoms that can form Hf-F bonds that correspond to a coverage of $9.5 \pm 0.3 \mathrm{Hf} / \mathrm{nm}^{2}$. Using the maximum coverage of Hf-F $9.0 \pm 0.3 \mathrm{Hf}-\mathrm{F} / \mathrm{nm}^{2}$ there will be about $0.95 \mathrm{~F}$ atoms per surface Hf. Similar to the analysis done in previous theoretical etch rate calculations for crystalline $\mathrm{Al}_{2} \mathrm{O}_{3},{ }^{45} \mathrm{HfO}_{2}$ and $\mathrm{ZrO}_{2},{ }^{44}$ the amount of $\mathrm{Hf}$ that can be etched is one-quarter of the Hf-F coverage which is $2.3 \pm 0.1 \mathrm{Hf} /\left(\mathrm{nm}^{2}\right.$ cycle) for $\mathrm{aHfO}_{2}$. As the surface concentration of $\mathrm{Hf}$ atoms is $9.5 \pm 0.3 \mathrm{Hf} / \mathrm{nm}^{2}$, this etch rate corresponds to 0.2 monolayer/cycle. This corresponds to $-78.8 \pm 0.8 \mathrm{ng} /\left(\mathrm{cm}^{2}\right.$ cycle $)$ and using our DFT density of bulk $\mathrm{aHfO}_{2}(9.62$ $\left.\mathrm{g} / \mathrm{cm}^{3}\right)$, our theoretical etch rate for $\mathrm{aHfO}_{2}$ is $-0.82 \pm 0.02 \AA /$ cycle. Our theoretical etch rate for $\mathrm{cHfO}_{2}$ is $-0.61 \pm 0.02 \AA /$ cycle. ${ }^{44}$ The theoretical etch rate for $\mathrm{aHfO}_{2}$ is greater than the theoretical etch rate for $\mathrm{cHfO}_{2}$ by $0.21 \AA$ //cycle. Etch rates calculated from experiment can differ with temperature and the reactant used in the second pulse. It was found experimentally using HF as the fluorinating reagent and DMAC as the ligand-exchange reagent at $250{ }^{\circ} \mathrm{C}$ the etch rate was $0.68 \AA /$ cycle for $\mathrm{aHfO}_{2}$ and $0.08 \AA /$ cycle for $\mathrm{cHfO}_{2} .{ }^{41}$ Using $\mathrm{HF}$ as the fluorinating reagent and $\mathrm{TiCl}_{4}$ as the ligand-exchange reagent at $250{ }^{\circ} \mathrm{C}$ the etch rate was $0.36 \AA /$ cycle for $\mathrm{aHfO}_{2}$ and $0.02 \AA /$ cycle for $\mathrm{cHfO}_{2} .{ }^{41}$ We therefore qualitatively show the enhanced etch rate for $\mathrm{aHfO}_{2}$ compared to $\mathrm{cHfO}_{2}$, and provide origins of this enhanced etching on $\mathrm{aHfO}_{2}$.

Unlike experimental etch rates, theoretical etch rates do not take kinetic effects into account. Hence, the maximum etch rate to remove a monolayer (ML) of material from $\mathrm{aHfO}_{2}$ is also calculated. For one ML removal, $18 \mathrm{Hf}$ atoms are used which requires a HfF coverage of $38.2 \pm 0.3 \mathrm{~F} / \mathrm{nm}^{2}$. An etch rate of $-3.47 \AA /$ cycle was computed for one ML removal using the same method for calculating the theoretical etch rate. If an experimental 
etch rate was greater than $-3.47 \AA$ /cycle it would suggest that subsurface Hf atoms are being etched and the reaction is no longer self-limiting. The published etch rates for metal oxides $^{41}$ are much lower than this maximum etch rate further confirming that self-limiting etching is indeed observed.

The difference seen in thermal ALE etch rates of amorphous and crystalline $\mathrm{HfO}_{2}$ may be due to higher density crystalline materials having bond lengths and configurations that are more uniform than for amorphous materials. ${ }^{41}$ Amorphous materials may have void regions and undercoordinated atoms that allows for more binding sites during fluorination. $\mathrm{HF}$ adsorption studies for crystalline $\mathrm{HfO}_{2}$ showed that every surface-bound $\mathrm{F}$ atom had a coordination number of one with surface Hf for Hf-F coverage of $7.0 \pm 0.3 \mathrm{~F} / \mathrm{nm}^{2}{ }^{44}$ For amorphous $\mathrm{HfO}_{2}$, the coordination number for surface-bound $\mathrm{F}$ atoms range from one to three, for a Hf-F coverage of $9.0 \pm 0.3 \mathrm{~F} / \mathrm{nm}^{2}$. The greater the surface is fluorinated; the more material can be removed and a greater etch rate is obtained.

\section{SUMMARY AND CONCLUSIONS}

In this paper, we present DFT calculations to understand the nature of the HF pulse on amorphous $\mathrm{HfO}_{2}$ for thermal ALE. A thermodynamic analysis of the self-limiting and spontaneous etch reactions representing the fluorination on amorphous $\mathrm{HfO}_{2}$ allowed us to predict whether the SE or SL reaction is favourable at a given temperature and a given pressure. At temperatures less than $520 \mathrm{~K}$, the HF reaction is found to be in the preferred self-limiting state. This is a relatively inexpensive way to screen the reactant molecules for ALE of any given substrate. The adsorption of $\mathrm{HF}$ molecules on amorphous $\mathrm{HfO}_{2}$ for $\mathrm{HF}$ coverages ranging from $1.1 \pm 0.3$ to $18.0 \pm 0.3 \mathrm{HF} / \mathrm{nm}^{2}$ along with analysis of $\mathrm{H}_{2} \mathrm{O}$ and 
$\mathrm{H}_{2} \mathrm{O}_{2}$ formation was studied. From this analysis, we predict a theoretical etch rate based on the maximum possible coverage of surface-bound $\mathrm{HF}$ for amorphous $\mathrm{HfO}_{2}$ which was calculated to be $-0.82 \pm 0.02 \AA /$ cycle. This computed etch rate for amorphous $\mathrm{HfO}_{2}$ is greater than the etch rate computed for crystalline $\mathrm{HfO}_{2}$ from our previous study. We can use the presented methodology for the first pulse on crystalline and amorphous metal oxides to examine other reagents such as $\mathrm{SF}_{4}$ and $\mathrm{XeF}_{2}$ with a similar analysis.

\section{SUPPLEMENTAL MATERIAL}

See supplementary material at [URL will be inserted by AIP Publishing] for the following (i) the pair distribution function of the amorphous $\mathrm{HfO}_{2}$ bulk model used in this study, (ii) figures of the mixed molecular and dissociative adsorption of the HF molecules at the $\mathrm{aHfO}_{2}$ surface and (iii) explanation of the \pm 0.3 error bar.

\section{ACKNOWLEDGMENTS}

We acknowledge support for this work from LAM Research and the Science Foundation Ireland-NSF China Partnership Program, NITRALD Grant number: 17/NSFC/5279. We are grateful for access to Tyndall computing facilities supported by SFI and the Irish Centre for High-End Computing, www.ichec.ie.

J.J.G.M. acknowledges the financial support from the FusionCAT project (No. 001-P001722) co-financed by the European Union Regional Development Fund within the framework of the ERDF Operational Program of Catalonia 2014-2020 with a grant of $50 \%$ of total cost eligible, and the access to HPC resources at the National Supercomputing 
Center in Shenzhen, acquired with the funding from the Postdoctoral Science Foundation

of China (Grant No. 2018M643152).

\section{DATA AVAILABILITY}

The data that support the findings of this study are openly available at

https://github.com/RitaMull/Thermal-ALE-aHfO2-using-HF

\section{REFERENCES}

${ }^{1}$ K.J. Kanarik, T. Lill, E.A. Hudson, S. Sriraman, S. Tan, J. Marks, V. Vahedi, and R.A. Gottscho, Journal of Vacuum Science \& Technology A: Vacuum, Surfaces, and Films 33, 020802 (2015).

2 S.M. George, Accounts of Chemical Research 53, 1151 (2020).

${ }^{3}$ S.M. George and Y. Lee, ACS Nano 10, 4889 (2016).

${ }^{4}$ Y. Lee and S.M. George, ACS Nano 9, 2061 (2015).

${ }^{5}$ A. Fischer, A. Routzahn, S.M. George, and T. Lill, Journal of Vacuum Science \& Technology A 39, 030801 (2021).

${ }^{6}$ Y. Lee, C. Huffman, and S.M. George, Chemistry of Materials 28, 7657 (2016).

${ }^{7}$ Y. Lee, J.W. DuMont, and S.M. George, ECS Journal of Solid State Science and Technology 4, N5013 (2015).

${ }^{8}$ Y. Lee and S.M. George, Journal of Vacuum Science \& Technology A 36, 061504 (2018).

${ }^{9}$ Y. Lee and S.M. George, Journal of Physical Chemistry C 123, 18455 (2019).

${ }^{10}$ J.W. DuMont, A.E. Marquardt, A.M. Cano, and S.M. George, ACS Applied Materials and Interfaces 9, 10296 (2017).

${ }^{11}$ Y. Lee, J.W. DuMont, and S.M. George, Chemistry of Materials 27, 3648 (2015).

${ }^{12}$ Y. Lee and S.M. George, ACS Nano 9, 2061 (2015).

${ }^{13}$ Y. Lee, J.W. DuMont, and S.M. George, Chemistry of Materials 28, 2994 (2016).

${ }^{14}$ J. Hennessy, C.S. Moore, K. Balasubramanian, A.D. Jewell, K. France, and S. Nikzad, Journal of Vacuum Science \& Technology A: Vacuum, Surfaces, and Films 35, 041512 (2017).

15 J.W. DuMont and S.M. George, The Journal of Chemical Physics 146, 052819 (2017).

${ }^{16}$ A. Fischer, A. Routzahn, Y. Lee, T. Lill, and S.M. George, Journal of Vacuum Science \& Technology A: Vacuum, Surfaces, and Films 38, 022603 (2020).

${ }^{17}$ J. Hennessy, A.D. Jewell, J.P. Jones, G.M. Crouch, and S. Nikzad, ACS Applied Materials and Interfaces 13, 4723 (2021).

${ }^{18}$ P.C. Lemaire and G.N. Parsons, Chemistry of Materials 29, 6653 (2017). 
19 J.C. Gertsch, A.M. Cano, V.M. Bright, and S.M. George, Chemistry of Materials 31, 3624 (2019).

${ }^{20}$ N.R. Johnson and S.M. George, ACS Applied Materials and Interfaces 9, 34435 (2017).

${ }^{21}$ D.R. Zywotko and S.M. George, Chemistry of Materials 29, 1183 (2017).

${ }^{22}$ Y. Lee, N.R. Johnson, and S.M. George, Chemistry of Materials 32, 5937 (2020).

${ }^{23}$ A.I. Abdulagatov and S.M. George, Journal of Vacuum Science \& Technology A 38, 022607 (2020).

${ }^{24}$ N.R. Johnson, H. Sun, K. Sharma, and S.M. George, Journal of Vacuum Science \& Technology A: Vacuum, Surfaces, and Films 34, 050603 (2016).

${ }^{25}$ Y. Lee and S.M. George, Chemistry of Materials 29, 8202 (2017).

${ }^{26}$ K. Shinoda, N. Miyoshi, H. Kobayashi, M. Izawa, K. Ishikawa, and M. Hori, Journal of Physics D: Applied Physics 52, 475106 (2019).

${ }^{27}$ T. Ohba, W. Yang, S. Tan, K.J. Kanarik, and K. Nojiri, Japanese Journal of Applied Physics 56, 06HB06 (2017).

${ }^{28}$ C. Kauppinen, S.A. Khan, J. Sundqvist, D.B. Suyatin, S. Suihkonen, E.I. Kauppinen, and M. Sopanen, Journal of Vacuum Science \& Technology A: Vacuum, Surfaces, and Films 35, 060603 (2017).

${ }^{29}$ V. Sharma, S.D. Elliott, T. Blomberg, S. Haukka, M.E. Givens, M. Tuominen, and M. Ritala, Chemistry of Materials 33, 2883 (2021).

${ }^{30}$ S.K. Natarajan, M. Nolan, P. Theofanis, C. Mokhtarzadeh, and S.B. Clendenning, Cite This: ACS Appl. Mater. Interfaces 12, 36680 (2020).

${ }^{31}$ P.C. Lemaire and G.N. Parsons, Chemistry of Materials 29, 6653 (2017).

${ }^{32}$ K.J. Kanarik, S. Tan, and R.A. Gottscho, J. Phys. Chem. Lett 9, 4814 (2018).

${ }^{33}$ G.D. Wilk, R.M. Wallace, and J.M. Anthony, Journal of Applied Physics 89, 5243 (2001).

${ }^{34}$ P. Raghu, C. Yim, F. Shadman, and E. Shero, AIChE Journal 50, 1881 (2004).

${ }^{35}$ P. Raghu, N. Rana, C. Yim, E. Shero, and F. Shadman, Journal of The Electrochemical Society - J ELECTROCHEM SOC 50, 1881 (2003).

${ }^{36}$ D.M. Hausmann, E. Kim, J. Becker, and R.G. Gordon, Chemistry of Materials 14, 4350 (2002).

${ }^{37}$ E. Cockayne, Journal of Applied Physics 103, 084103 (2008).

${ }^{38}$ P.R. Chalker, M. Werner, S. Romani, R.J. Potter, K. Black, H.C. Aspinall, A.C. Jones, C.Z. Zhao, S. Taylor, and P.N. Heys, Applied Physics Letters 93, 182911 (2008).

${ }^{39}$ R. Rahman, E.C. Mattson, J.P. Klesko, A. Dangerfield, S. Rivillon-Amy, D.C. Smith, D. Hausmann, and Y.J. Chabal, ACS Applied Materials \& Interfaces 10, 31784 (2018).

${ }^{40}$ W. Xie, P.C. Lemaire, and G.N. Parsons, ACS Applied Materials \& Interfaces 10, 9147 (2018).

${ }^{41}$ J.A. Murdzek and S.M. George, Journal of Vacuum Science \& Technology A 38, 022608 (2020).

${ }^{42}$ J.A. Murdzek, A. Rajashekhar, R.S. Makala, and S.M. George, Journal of Vacuum Science \& Technology A 39, 042602 (2021).

${ }^{43}$ J. Chen, W. Jong Yoo, and D.S.H. Chan, Journal of The Electrochemical Society 153, G483 (2006).

${ }^{44}$ R. Mullins, S. Kondati Natarajan, S.D. Elliott, and M. Nolan, Chemistry of Materials 32, 3414 (2020). 
${ }^{45}$ S. Kondati Natarajan and S.D. Elliott, Chemistry of Materials 30, 5912 (2018).

${ }^{46}$ C. Fang, Y. Cao, D. Wu, and A. Li, Progress in Natural Science: Materials International 28, 667 (2018).

${ }^{47}$ G. Kresse and J. Furthmüller, Physical Review B 54, 11169 (1996).

48 J.P. Perdew, K. Burke, and M. Ernzerhof, Physical Review Letters 77, 3865 (1996).

${ }^{49}$ G. Kresse and D. Joubert, Physical Review B 59, 1758 (1999).

${ }^{50}$ V. Sharma, S. Kondati Natarajan, S.D. Elliott, T. Blomberg, S. Haukka, M.E. Givens, M. Tuominen, and M. Ritala, Advanced Materials Interfaces 2101085 (2021).

${ }^{51}$ S. Plimpton, Journal of Computational Physics 117, 1 (1995).

${ }^{52}$ G. Broglia, G. Ori, L. Larcher, and M. Montorsi, Modelling and Simulation in Materials Science and Engineering 22, 065006 (2014).

${ }^{53}$ D. Ceresoli and D. Vanderbilt, Physical Review B 74, 125108 (2006).

${ }^{54}$ W. Shen, N. Kumari, G. Gibson, Y. Jeon, D. Henze, S. Silverthorn, C. Bash, and S. Kumar, Journal of Applied Physics 123, 085113 (2018).

55 J. Strand, M. Kaviani, V. v Afanas'ev, J.G. Lisoni, and A.L. Shluger, Nanotechnology 29, 125703 (2018).

${ }^{56}$ A. Togo and I. Tanaka, Scripta Materialia 108, 1 (2015).

${ }^{57}$ TURBOMOLE v6.2 2010, A Development of University of Karlsruhe and

Forschungszentrum Karlsruhe GmbH, 1989-2007, TURBOMOLE GmbH, since 2007.

Available from http://www.turbomole.com (Last Accessed 27 Nov, 2019).

${ }^{58}$ S.G. Balasubramani, G.P. Chen, S. Coriani, M. Diedenhofen, M.S. Frank, Y.J.

Franzke, F. Furche, R. Grotjahn, M.E. Harding, C. Hättig, A. Hellweg, B. Helmich-Paris, C. Holzer, U. Huniar, M. Kaupp, A. Marefat Khah, S. Karbalaei Khani, T. Müller, F.

Mack, B.D. Nguyen, S.M. Parker, E. Perlt, D. Rappoport, K. Reiter, S. Roy, M. Rückert, G. Schmitz, M. Sierka, E. Tapavicza, D.P. Tew, C. van Wüllen, V.K. Voora, F. Weigend, A. Wodyński, and J.M. Yu, Journal of Chemical Physics 152, 184107 (2020).

${ }^{59}$ A. Schäfer, H. Horn, and R. Ahlrichs, The Journal of Chemical Physics 97, 2571 (1992).

${ }^{60}$ A. Schäfer, C. Huber, and R. Ahlrichs, The Journal of Chemical Physics 100, 5829 (1994).

${ }^{61}$ T. v. Perevalov, V.A. Gritsenko, S.B. Erenburg, A.M. Badalyan, H. Wong, and C.W. Kim, Journal of Applied Physics 101, 053704 (2007).

${ }^{62}$ T.J. Chen and C.L. Kuo, Journal of Applied Physics 110, 064105 (2011).

${ }^{63}$ Y. Wang, F. Zahid, J. Wang, and H. Guo, Physical Review B - Condensed Matter and Materials Physics 85, 224110 (2012).

${ }^{64}$ W.L. Scopel, A.J.R. da Silva, and A. Fazzio, Physical Review B - Condensed Matter and Materials Physics 77, 172101 (2008).

${ }^{65}$ G.H. Chen, Z.F. Hou, and X.G. Gong, Applied Physics Letters 95, 102905 (2009).

${ }^{66}$ Y.R. Luo, Comprehensive Handbook of Chemical Bond Energies 1 (2007). 